\section{Time to stop preventable deaths from unsterile traditional male circumcision practices}

To the Editor: Once again the nation is outraged by the now familiar annual tale of how a number of initiates undergoing traditional male circumcision in several provinces have paid with permanent disability, or the ultimate penalty of death, for taking part in cultural practices that have outlived their value in today's South Africa. While we respect the rights of people to engage in culturally important initiation practices, it is unacceptable that every year during the winter months a large number of initiates continue to die or be maimed for life. The $S A M J$ alluded to the 'Astonishing indifference to deaths due to botched ritual circumcision' fully a decade ago, ${ }^{[1]}$ and yet this year is seeing a repeat of the now familiar tale - the suffering of innocent young men and boys in order to become men. It was announced on Thursday 3 July 2014 that there had been already 23 initiation fatalities (19 in the Eastern Cape Province, three in Mpumalanga and one in the Western Cape) during this initiation season, which started in July. This is in spite of the supposed 'zero tolerance to initiation fatalities' campaign led by the Department of Traditional Affairs together with various stakeholders such as the National House of Traditional Leaders, the Department of Health, the South African Police Services, the Commission for the Promotion and Protection of the Rights of Cultural, Religious and Linguistic Communities and the Congress of Traditional Leaders. Sadly, by the time of submission of this letter a fortnight later, more deaths had occurred. Every year we have been promised action, and every year more young men die or are maimed for life.

We the undersigned concerned scientists and parents call for immediate action by our government to stop the unacceptable deaths and penile amputations among young initiates undergoing traditional male circumcision by abolishing unsterile traditional male circumcision surgical practices with immediate effect. Our nation cannot afford this annual ritual of unwarranted slaughter and maiming of its sons to continue unabated. The time has come to show leadership in dealing with this major public health issue, which is a cause of great concern and embarrassment to all our citizens. We believe that decisive action cannot be postponed any longer. Even one more death or penile amputation of an initiate is one too many to accept.

We call on all traditional leaders from the various communities that engage in traditional male circumcision, and on politicians, to speak out publicly against this practice and follow King Goodwill Zwelithini's historic and successful call in 2010 for Zulu initiates to be medically circumcised. Let us remember, culture is created, and it can lead to harmful or safe cultural practices. It is in our hands to change this situation once and for all.

\section{Leickness Simbayi \\ Olive Shisana \\ Geoffrey Setswe}

Human Sciences Research Council, South Africa

Glenda Gray

Medical Research Council, South Africa

Francois Venter

Wits Reproductive Health and HIV Institute, Johannesburg, South Africa

\author{
Dan Ncayiyana \\ Thomas Rehle \\ Human Sciences Research Council, South Africa \\ profdjn@gmail.com
} 1. Ncayiyana D. Astonishing indifference to deaths due to botched ritual circumcision. S Afr Med J
2003;93(8):546.

S Afr Med J 2014;104(8):521. DOI:10.7196/SAMJ.8687 